\title{
STUDY OF SEIZURE DISORDER IN CHILDREN IN CORRELATION WITH COMPUTERIZED TOMOGRAPHY AND ELECTROENCEPHALOGRAPHY
}

\author{
Sidhartha Kiran Gollapalli1, Sirigineedi Chandra Sekhar², Duggirala Manikyamba³, Amujuri Krishna Prasad ${ }^{4}$, Kovvuri Adi Reddy 5
}

${ }_{1}^{1}$ Assistant Professor, Department of Paediatrics, Rangaraya Medical College, Kakinada.

${ }^{2}$ Assistant Professor, Department of Paediatrics, Rangaraya Medical College, Kakinada.

3 Professor \& HOD, Department of Paediatrics, Rangaraya Medical College, Kakinada.

${ }^{4}$ Associate Professor, Department of Paediatrics, Rangaraya Medical College, Kakinada.

5Junior Resident, Department of Paediatrics, Rangaraya Medical College, Kakinada.

\section{ABSTRACT}

\section{BACKGROUND}

Seizure disorders are fairly common in children. Almost $5 \%$ of children at risk of experiencing a seizure. The aetiology of seizures is different in India and other developing countries as compared to the developed world. Tuberculoma and neurocysticercosis have relatively high frequency in India. ${ }^{1}$ Most of the Indian studies on seizure disorders were done in mixed population of adults and children. Only few Indian studies looked at the prevalence, incidence, causative factors and other aspects of childhood seizures. The present study emphasizing on clinical profile of seizures concentrating only on paediatric age group and to evaluate the role of EEG and CT scan brain as a diagnostic aid in various seizure disorders in children. This study focusses on CT findings, which are more easily available in peripheries where MRI facilities may not be available, though MRI may be superior to CT in identifying the lesions.

\section{STUDY METHODS}

The study includes 108 children from 1 year to less than 12 years of age with various seizure disorders, who are coming to Paediatric Outpatient and Inpatient Department, Govt. General Hospital, Kakinada, from November 2014 to October 2015 . This is a cross sectional observation study.

\section{RESULTS}

Out of the 108 cases studied, half of the patients $(n=55,50.9 \%)$ presented with GTCS. Complex partial seizures is the second most common type of seizure disorder $(n=29,26.9 \%)$. Maximum number of children were in the 3-10 years' age group $(n=65,60.18 \%)$. Maximum number of patients presented during $12^{\text {th }}$ year $(n=17,15.7 \%)$ followed by $8^{\text {th }}$ year $(n=14,13 \%) .0$ ut of 108 children studied, 70 (64.81\%) are male children and 38 (35.19\%) are female children. The male:female ratio is 1.8:1. Among the patients with abnormal CT, solitary tuberculoma was the most frequent abnormality which was detected in 22 patients (40\%), Neurocysticercosis was the second common abnormality detected in the present study. Among the patients with abnormal EEG, features suggestive of generalized seizure disorder was present in 39 cases (60.94\%). One hemisphere slowing suggestive of underlying focus is present in 25 cases (39.06\%), left side being involved in more number of patients than the right side. In the present study among patients with GTCS, EEG abnormality alone was found in $25.45 \%$ cases, CT abnormality alone was found in $23.64 \%$ cases and both CT and EEG were abnormal in $21.82 \%$ cases.

\section{CONCLUSION}

Seizure disorders were found to be more common in male children compared to female children. The male:female ratio is $1.8: 1 .^{2}$ The incidence of seizure disorders was found to be high in children above 3 years of age. Generalized seizures were more common than partial seizures. Among the generalized seizures, generalized tonic clonic seizures were common and among partial seizures complex partial seizures were common. In the present study, CT scan revealed structural abnormalities more commonly in partial seizures (74\%) than in generalized seizures (41\%). The most common finding observed by CT scan was tuberculoma followed by neurocysticercosis. EEG abnormalities were found in $50 \%$ of cases of generalized seizures and $74 \%$ of cases of partial seizures.

\section{KEYWORDS}

EEG Abnormality, Abnormal CT Scan, Epilepsy, Seizure Disorder, Tuberculoma.

HOW TO CITE THIS ARTICLE: Gollapalli SK, Sekhar SC, Manikyamba D, et al. Study of seizure disorder in children in correlation with computerized tomography and electroencephalography. J. Evolution Med. Dent. Sci. 2016;5(33):1809-1813,

Financial or Other, Competing Interest: None.

Submission 08-03-2016, Peer Review 04-04-2016,

Acceptance 09-04-2016, Published 23-04-2016.

Corresponding Author:

Dr. Kovvuri Adi Reddy,

Junior Resident,

Department of Paediatrics,

Rangaraya Medical College,

Kakinada.

E-mail: adi9949844121@gmail.com

DOI: $10.14260 /$ jemds $/ 2016 / 426$

\section{INTRODUCTION}

Seizures are an important cause of morbidity and mortality in childhood. It is important to establish accurate diagnosis, localisation of lesion to appropriately manage such patients. EEG as a diagnostic aid and also helpful in classifying the seizure, suggest an aetiology, guide clinical management as well as provides evidence of localisation. Because of a significant chance of finding some structural cerebral lesion, neuroimaging procedure such as CT scan brain is indicated essentially for every child with seizures. 
In view of above facts, we conducted this study to determine various aetiological factors in admitted children with seizures and also to evaluate the role of EEG and CT scan as a diagnostic aid in various seizure disorders in children.

\section{MATERIALS AND METHODS}

\section{Source of Data}

Children presenting with convulsions from 1 to 12 years of age in Paediatrics Outpatient and Inpatient Departments in Government General Hospital, Rangaraya Medical College, Kakinada, from November 2014 to October 2015 were the source of cases for study.

\section{Sampling Method}

Simple random sampling.

\section{Inclusion Criteria}

The study includes children from 1 to 12 years of age with complaints of convulsions.

\section{Exclusion Criteria}

Febrile seizures and acute CNS insults like meningitis, neonatal seizures were excluded. Children presenting with seizures below l year age were excluded from the study, because the investigative workup of inborn errors of metabolism which is one of the important cause for seizures in childhood below 1 year was not available in our Institute.

\section{Method of Collection of Data}

Children presenting with convulsions from 1 to 12 years of age; after informed consent a detailed history was taken from patient's attendant and other reliable sources with regard to the aura, nature of the seizure, duration, postictal events and other associated features of seizures, family history, aggravating and precipitating factors. Patients having partial or generalized seizures according to ILAE classification. ${ }^{3}$ according to which partial seizures include a variety of clinical manifestations including focal motor, somatosensory or special sensory phenomenon including visual, auditory, olfactory, gustatory hallucinations and autonomic symptoms. If it is associated with unconsciousness, then it is termed as a complex partial seizure. ${ }^{4}$ History of contact with tuberculous patients in the family and neighbourhood was enquired. Nutritional and immunization status was assessed. Tuberculin test, X-ray chest for radiological evidence of intrathoracic tuberculosis, microscopic examination of sputum and gastric aspirate, histology of the lymph node were done wherever necessary.

All the patients were subjected to CT scan brain (Plain and Contrast if necessary) and EEG. The CT scans were evaluated for the type of lesion, location of the lesion, the displacement of intracranial structures and the presence of ring shadows, hydrocephalus and surrounding oedema. EEG recordings were done in the interictal period on 16 channel EEG machine with the child awake or asleep depending on the cooperation.

The child is subjected to provocative measures like hyperventilation and photic stimulation. EEG was evaluated for abnormalities of background, spikes, polyspikes, slowing, hypsarrhythmia and EEG pattern specific for any specific syndrome were looked. The results obtained were analysed with different statistically significant tests and presented in tables.

\section{OBSERVATION AND RESULTS}

\begin{tabular}{|c|c|c|}
\hline Seizure Type & No. of Cases & $\%$ \\
\hline GTCS & 55 & $50.93 \%$ \\
\hline CPS & 29 & $26.85 \%$ \\
\hline SPS & 6 & $5.56 \%$ \\
\hline Atonic & 2 & $1.85 \%$ \\
\hline Absence & 2 & $1.85 \%$ \\
\hline Myoclonic & 1 & $0.93 \%$ \\
\hline Unclassified & 13 & $12.04 \%$ \\
\hline Total & 108 & 100 \\
\hline \multicolumn{3}{|c|}{$\begin{array}{c}\text { Table 1: Distribution of Cases } \\
\text { according to Seizure Type }\end{array}$} \\
\hline
\end{tabular}

Out of the 108 cases studied, half of the patients $(\mathrm{n}=55,50.9 \%)$ presented with GTCS. 5 Complex partial seizures is the second most common type of seizure disorder $(n=29,26.9 \%)$. Seizures with no specific characteristics like patients presenting only with head nodding, unconscious with froth from mouth and generalized flaccidity, self-induced photosensitive epilepsy and abdominal epilepsy were grouped under unclassified seizures.

\begin{tabular}{|c|c|c|}
\hline Age of Onset & No. & $\mathbf{\%}$ \\
\hline 1- 3 yrs. & 20 & $18.51 \%$ \\
\hline 3 - 10 yrs. & 65 & $60.18 \%$ \\
\hline 10-12 yrs. & 23 & $21.29 \%$ \\
\hline \multicolumn{2}{|c|}{ Table 2: Age Distribution of Seizures } \\
\hline
\end{tabular}

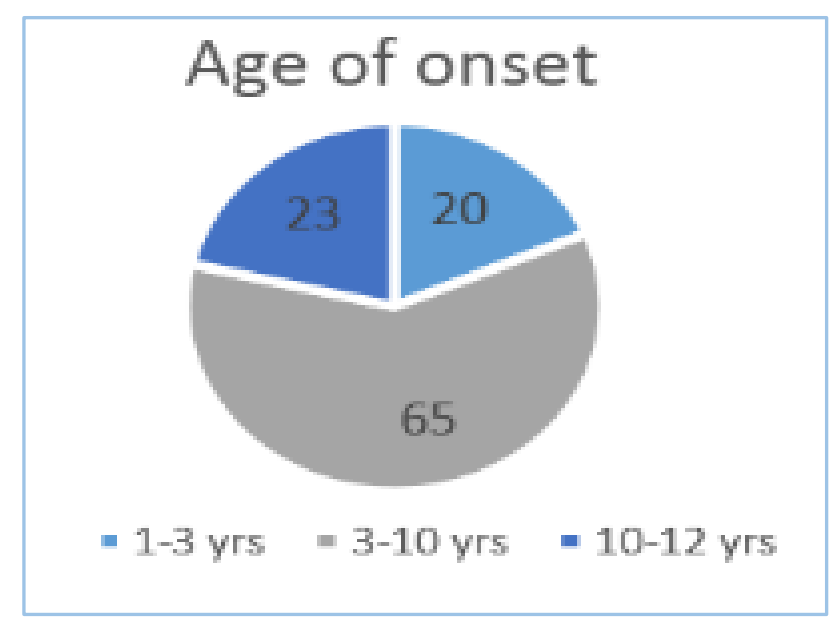

Children were divided into three categories according to age. Maximum number of children were in the 3-10 years' age. ${ }^{6}$ group $(n=65,60.18 \%)$. Nearly one-fifth of children were in 10-12 years' age group. Maximum number of patients presented during $12^{\text {th }}$ year $(\mathrm{n}=17,15.7 \%)$ followed by $8^{\text {th }}$ year $(n=14,13 \%)$.

\begin{tabular}{|c|c|c|c|}
\hline & 1-3yrs. & 3-10yrs. & $>10$ \\
\hline GTCS & $\begin{array}{c}13 \\
(23.63 \%)\end{array}$ & $\begin{array}{c}28 \\
(50.90 \%)\end{array}$ & $\begin{array}{c}14 \\
(25.45 \%)\end{array}$ \\
\hline Absence & - & $2(100 \%)$ & - \\
\hline Atonic & - & - & $2(100 \%)$ \\
\hline Myoclonic & $1(100 \%)$ & - & - \\
\hline Complex partial & $4(13.79 \%)$ & 21 & $4(13.79 \%)$ \\
\hline Simple partial seizures & - & $4(66.66 \%)$ & $2(33.33 \%)$ \\
\hline Unclassified & $3(23.07 \%)$ & $8(61.53 \%)$ & $2(15.38 \%)$ \\
\hline
\end{tabular}


In the present study, 2 cases of absence seizures are recorded. In both of them, the age of onset was after 6 years. One case of myoclonic seizures was recorded at age 18 months. Other type of seizures like GTCS, CPS, SPS and Atonic were more common in older age group. ${ }^{7}$

\begin{tabular}{|c|c|c|}
\hline Age (Years) & Male & Female \\
\hline $1-3$ & 7 & 1 \\
\hline $3-10$ & 47 & 20 \\
\hline $10-12$ & 16 & 17 \\
\hline \multicolumn{2}{|c|}{ Table 4: Age \& Sex Distribution } \\
\hline
\end{tabular}



Out of 108 children studied, 70 (64.81\%) are male children and 38 (35.19\%) are female children. The male:female ratio is 1.8:1. Maximum number of children in both males and females were seen in the age group of 3-10 yrs. ( $p=0.038$, significant).

\begin{tabular}{|c|c|}
\hline Normal & $53(49.07 \%)$ \\
\hline Abnormal & $55(50.93 \%)$ \\
\hline \multicolumn{2}{|c|}{ Table 5: CT Findings } \\
\hline
\end{tabular}

\begin{tabular}{|c|c|c|}
\hline $\begin{array}{c}\text { Structural Abnormalities in CT } \\
\text { Scan Brain }\end{array}$ & $\begin{array}{c}\text { No. of } \\
\text { Cases }\end{array}$ & $\mathbf{\%}$ \\
\hline Tuberculoma (Single) & 22 & 40 \\
\hline Tuberculoma (Multiple) & 3 & 5.45 \\
\hline Neurocysticercosis & 15 & 27.27 \\
\hline Infarct & 2 & 3.64 \\
\hline $\begin{array}{c}\text { Partial agenesis of corpus } \\
\text { callosum }\end{array}$ & 1 & 1.82 \\
\hline $\begin{array}{c}\text { Complete agenesis of corpus } \\
\text { callosum }\end{array}$ & 1 & 1.82 \\
\hline Venous sinus thrombosis & 1 & 1.82 \\
\hline Porencephalic cyst & 2 & 3.64 \\
\hline Cerebral and cerebellar atrophy & 1 & 1.82 \\
\hline Gliotic changes & 4 & 7.27 \\
\hline Arachnoid cyst & 1 & 1.82 \\
\hline Thalamic glioma & 1 & 1.82 \\
\hline Abscess & 1 & 1.82 \\
\hline Total & $\mathbf{5 5}$ & $\mathbf{1 0 0}$ \\
\hline \multicolumn{2}{|c|}{ Table 6 } \\
\hline \multicolumn{2}{|c|}{} \\
\hline
\end{tabular}

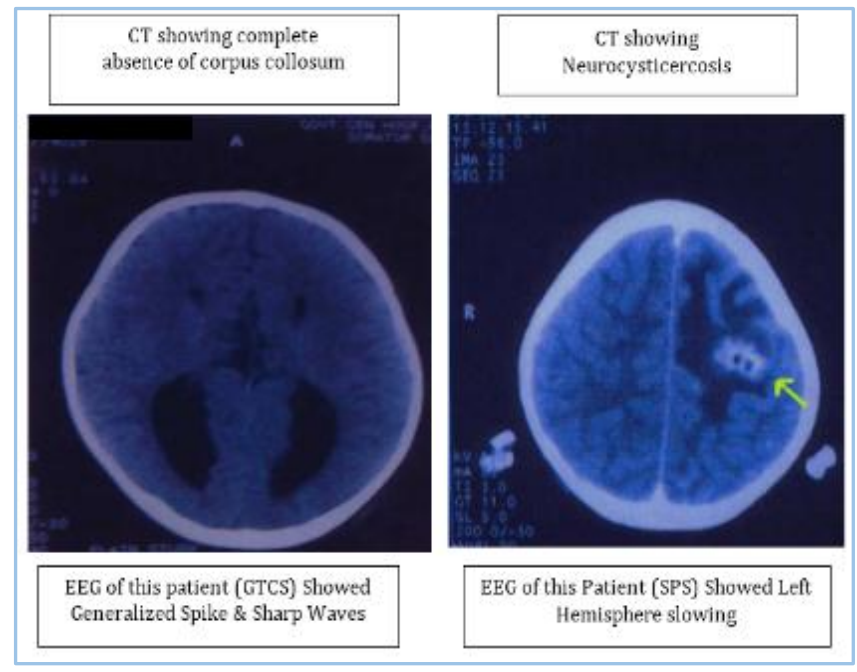

CT was normal in $49.07 \%$ of the patients. CT revealed different structural abnormalities in the remaining $50.93 \%$ of study subjects. Among the patients with abnormal CT, solitary tuberculoma was the most frequent abnormality which was detected in 22 patients (40\%). Neurocysticercosis was the second common abnormality detected in the present study in 15 patients $(27.27 \%)$. Gliotic changes were seen in five patients (9.09\%). Infarct, porencephalic cysts seen in 2 cases each (3.64\%).

\section{Age Wise Distribution of CT Abnormalities}

\begin{tabular}{|c|c|c|c|c|}
\hline & $\begin{array}{c}\text { No. of } \\
\text { Cases }\end{array}$ & 1-3 years & $\mathbf{3 - 1 0}$ years & 10-12 years \\
\hline CT Normal & 53 & $14(70 \%)$ & $29(44.62 \%)$ & $10(43.48 \%)$ \\
\hline CT Abnormal & 55 & $6(30 \%)$ & $36(55.38 \%)$ & $13(56.52 \%)$ \\
\hline \multicolumn{5}{|c|}{ Table 7 } \\
\hline
\end{tabular}

$50.93 \%$ of cases showed CT abnormalities. Most of the CT abnormalities were in $10-12$ years' age group (56.52\%). But as the age increases neurocysticercosis increased in frequency (25\% in $3-10$ years vs. $46.15 \%$ in $10-12$ years' age group) than tuberculosis. ${ }^{8}$ Multiple tuberculoma occurred in younger age group (66.66\% in 1-3 years) and as age increases majority are single tuberculoma.

Incidence of CT Abnormalities in Different Seizure Types

\begin{tabular}{|c|c|c|c|}
\hline Seizure Type & Total Cases & CT Normal & CT Abnormal \\
\hline GTCS & 55 & $31(56.36 \%)$ & $24(43.64 \%)$ \\
\hline CPS & 29 & $9(31.03 \%)$ & $20(68.97 \%)$ \\
\hline SPS & 6 & 0 & $6(100 \%)$ \\
\hline Atonic & 2 & $2(100 \%)$ & 0 \\
\hline Myoclonic & 1 & 0 & $1(100 \%)$ \\
\hline Absence & 2 & $2(100 \%)$ & 0 \\
\hline Unclassified & 13 & $9(69.23 \%)$ & $4(30.77 \%)$ \\
\hline \multicolumn{4}{|c|}{ Table 8 } \\
\hline
\end{tabular}

CT scans is more informative in partial seizures where almost $75 \%$ of scans (26/35) showed abnormalities. ${ }^{9} 100 \%$ cases of SPS showed CT abnormality, but only $68.97 \%$ of CPS showed CT abnormality. 
In generalized seizures, the percentage of CT abnormality was only $41.67 \%$, but it was high for myoclonic (100\%) and GTCS (43.64\%).

\begin{tabular}{|c|cc|}
\hline Normal & 44 & $(40.74 \%)$ \\
\hline Abnormal & 64 & $(59.26 \%)$ \\
\hline \multicolumn{2}{|c|}{ Table 9: EEG Abnormalities } \\
\hline
\end{tabular}

\begin{tabular}{|c|c|c|}
\hline $\begin{array}{c}\text { Different EEG } \\
\text { Abnormalities }\end{array}$ & $\begin{array}{l}\text { No. of } \\
\text { Cases }\end{array}$ & Percentage \\
\hline Generalized spikes & 11 & $17.19 \%$ \\
\hline Generalized polyspikes & 3 & $4.69 \%$ \\
\hline Generalized slowing & 20 & $31.25 \%$ \\
\hline Generalized slow \& spike & 2 & $3.13 \%$ \\
\hline Generalized $3 \mathrm{~Hz} /$ spike & 3 & $4.69 \%$ \\
\hline Right hemisphere slowing & 3 & $4.69 \%$ \\
\hline Left hemisphere slowing & 22 & $34.38 \%$ \\
\hline Total & 64 & 100 \\
\hline \multicolumn{3}{|c|}{ Table 10: Different EEG Abnormalities } \\
\hline
\end{tabular}

EEG was normal in $40.74 \%$ of the patients. It revealed different abnormalities in the remaining $59.26 \%$ of study subjects. Among the patients with abnormal EEG, features suggestive of generalized seizure disorder was present in 39 cases $(60.94 \%)$ of which generalized spikes were present in 11 cases, generalized polyspikes in 3 cases, generalized slowing in 20 cases, both slow and spike waves in 2 cases and generalized $3 \mathrm{~Hz}$ spike wave activity in 3 cases. One hemisphere slowing suggestive of underlying focus is present in 25 cases (39.06\%), left side being involved in more number of patients than the right side.

\begin{tabular}{|c|c|c|c|}
\hline \multirow{2}{*}{$\begin{array}{c}\text { Seizure } \\
\text { Type }\end{array}$} & \multirow{2}{*}{$\begin{array}{c}\text { No. of } \\
\text { Cases }\end{array}$} & \multicolumn{2}{|c|}{ EEG } \\
\cline { 3 - 4 } & 55 & $29(52.73 \%)$ & $26(47.27 \%)$ \\
\hline GTCS & 29 & $7(24.14 \%)$ & $22(75.86 \%)$ \\
\hline CPS & 6 & $2(33.33 \%)$ & $4(66.67 \%)$ \\
\hline SPS & 2 & $1(50 \%)$ & $1(50 \%)$ \\
\hline Atonic & 1 & 0 & $1(100 \%)$ \\
\hline Myoclonic & 2 & 0 & $2(100 \%)$ \\
\hline Absence & 13 & $5(38.46 \%)$ & $8(61.54 \%)$ \\
\hline Unclassified & \multicolumn{4}{|c|}{ Table 11: Incidence of EEG } \\
\hline \multicolumn{4}{|c}{ Abnormalities in Different Seizure Types } \\
\hline
\end{tabular}

The positive yield of EEG was shown to be more in absence (100\%), myoclonic (100\%) and partial seizures ( 26 of 35 cases, $74.29 \%$ ) - CPS (75.86\%), SPS (66.67\%). It was poor in GTCS only (47.27\%), as the electrical discharges from deep seated lesion could not be picked up by scalp EEG.

\begin{tabular}{|c|c|c|c|c|c|}
\hline \multirow{2}{*}{$\begin{array}{c}\text { Seizure } \\
\text { Type }\end{array}$} & \multicolumn{5}{|c|}{ Both CT and EEG Done } \\
\cline { 2 - 6 } & Total & $\begin{array}{c}\text { Both } \\
\text { Normal }\end{array}$ & $\begin{array}{c}\text { Both } \\
\text { Abnormal }\end{array}$ & $\begin{array}{c}\text { Only EEG } \\
\text { Abnormal }\end{array}$ & $\begin{array}{c}\text { Only CT } \\
\text { Abnormal }\end{array}$ \\
\hline GTCS & 55 & $16(29.09 \%)$ & $12(21.82 \%)$ & $\begin{array}{c}14 \\
(25.45 \%)\end{array}$ & $\begin{array}{c}13 \\
(23.64 \%)\end{array}$ \\
\hline CPS & 29 & $3(10.35 \%)$ & $16(55.17 \%)$ & $6(20.69 \%)$ & $4(13.79 \%)$ \\
\hline
\end{tabular}

\begin{tabular}{|c|c|c|c|c|c|}
\hline SPS & 6 & 0 & $4(66.66 \%)$ & 0 & $2(33.33 \%)$ \\
\hline Atonic & 2 & $1(50.00 \%)$ & 0 & $1(50.00 \%)$ & 0 \\
\hline Myoclonic & 1 & 0 & $1(100 \%)$ & 0 & 0 \\
\hline Absence & 2 & 0 & 0 & $2(100 \%)$ & 0 \\
\hline Unclassified & 13 & $3(23.08 \%)$ & $2(15.38 \%)$ & $6(46.15 \%)$ & $2(15.38 \%)$ \\
\hline Table 12: Correlation between EEG and CT Findings in Relation to \\
Type of Seizures \\
\hline
\end{tabular}

In the present study among patients with GTCS, EEG abnormality alone was found in $25.45 \%$ cases, CT abnormality alone was found in $23.64 \%$ cases and both CT and EEG were abnormal in $21.82 \%$ cases. Among the patients with SPS more than half, that is $66.66 \%$ showed abnormalities in both CT and EEG. In patients with CPS 55.17\% cases showed abnormalities in both CT and EEG. In the present study, both the patients with absence seizures showed EEG abnormality alone with normal CT scan.

\section{DISCUSSION}

In this study of 108 cases of childhood seizures between the ages of $1-12$, only 14 cases $(12.96 \%)$ were reported to have seizures before 3 years of age. The male:female ratio in our study is $1.8: 1$. The incidence of generalized seizures were $55.56 \%$ and partial seizures were $32.40 \%$. Among the partial seizures, CPS (26.85\%) is more common than SPS (5.56\%) in our study. This is in correlation with the study of Homes et al ${ }^{10}$ and Kramer et al.11 Of the generalized seizures, GTCS is the commonest type of seizure in our study comprising $91.67 \%$. Of the partial seizures, CPS is the commonest type $82.86 \%$, but SPS was the commonest type of seizure in the study conducted by Maytel J et al. ${ }^{12}$ The positive yield of CT scans in our study is $74.29 \%$ (26/35 cases) with partial seizures and $41.67 \%(25 / 60)$ in cases with generalized seizures. Similar observations were reported by Yang et $\mathrm{al}^{9}$ who observed abnormal CT scan in 52\% patients of partial seizure disorder. In contrast to it, Washimkar et al $^{1}$ observed abnormal CT scan in $73 \%$ of patients with partial seizures.

The positive yield of EEG in our study is $59.26 \%$. In Mark A King study. 13 51\% of patients with seizures showed epileptiform activity in the first EEG. In our study there is a high yield of EEG in partial seizures (74.29\%) compared to generalized seizures (50\%), whereas in Mark A King study. ${ }^{13}$ there is a high yield of EEG in generalized seizures Vs. partial seizures (68\% Vs. $44 \%)$. In this study, both the 2 cases of absence seizures showed $3 /$ sec spike and wave discharge after subjecting the child to hyperventilation for 3 minutes. The observed percentage of interictal EEG abnormalities in absence seizures is $100 \%$.

In a study by Smith et al on partial seizures, $17 / 18$ patients (94.44\%) with SPS and 18/24 (75\%) patients with CPS showed abnormal interictal EEG findings. In our study $4 / 6(66.67 \%)$ cases of SPS and 22/29 (75.86\%) cases of CPS showed abnormal interictal EEG findings. Altogether, the value of EEG in identifying the seizure pattern is less with GTCS and more with absence and partial seizures. The value of CT in identifying the lesion is more in partial seizures (Especially SPS) than generalized seizures. 


\section{CONCLUSION}

GTCS were the most common type of seizures followed by complex partial seizures. The prevalence of GTCS was $50.93 \%$ and of complex partial seizures was $26.85 \%$. Inflammatory granulomas were the most common underlying cause of seizures. Most of the granulomas being tuberculomas. CT and EEG remain important tools of investigation in evaluation of childhood seizures, more so in partial seizures. Seizure disorders were found to be more common in male children compared to female children with male:female ratio of 1.8:1. The incidence of seizure disorders was found to be high in children above 3 years of age. In the present study, CT scan revealed structural abnormalities more commonly in partial seizures (74\%) than in generalized seizures (41\%). EEG abnormalities were found in $50 \%$ of cases of generalized seizures and $74 \%$ of cases of partial seizures. It is recommended that every case of idiopathic seizures must be evaluated with EEG as well as neuroimaging to establish the cause and to decide therapy and prognosis of seizure disorder.

\section{REFERENCES}

1. Washimkar SN, Holay MP, Fusey SM. Evaluation of focal seizures by computerized tomography. JAPI 1996;44:95960.

2. Ramesh Baheti, Gupta BD, Rajesh Baheti, et al. A study of CT and EEG findings in patients with generalized or partial seizures in Western Rajasthan. JIACM 2003;4(1):25-9.

3. Commission on classification and terminology of the international league against epilepsy. Proposal for revised clinical and electroencephalographic classification of epileptic seizures. Epilepsia 1981;22(4):489-501.
4. Kliegman, Stanton, St. Geme, et al. Nelson text book of pediatrics. Elsevier 2015;20 th ed:3888.

5. McGohan JP, Dubin AB, Hill RP. The evaluation of seizure disorders by computerised tomography. J Neurosurg 1979;50(3):328-32.

6. Kumar R, Navjivan S, Kohli N, et al. Clinical correlates of CT abnormality in generalized childhood epilepsy in India. Journal of Tropical Pediatrics 1997;43(4):199-203.

7. Shridharan R, Radhakrishan K, Ashok PP, et al. A epidemological and clinical study of epilepsy. Epilepsia 1986;27(1):60-5.

8. Mani KS, Rangan G, Srinivas HV, et al. The yelandur study: a community based approach to epilepsy in rural South Indiaepidemiological aspects. Seizure 1998;7(4):281-8.

9. Yang PJ, Poul EB, Michael EC, et al. Computed tomographyand childhood seizure disorders. Neurology 1979;29(8):1084-8.

10. Homes S, Ni XS, Dutt N, et al. EEG, CT and neurosonographic findings in patients with post-ischaemic seizures. J Neurol Sci 1995;132(1):57-60.

11. Kramer U, Nevo V, Meyer JJ, et al. Neuroimaging of children with partial seizures. Seizure 1998;7(2):115-8.

12. Maytel J, Krauss JM, Novak G, et al. The role of brain computerized tomography in evaluating children with new onset of seizures in the emergency departments. Epilepsia 2000;41(8):950-4.

13. Mark A King, Newton MR, Jackson GD, et al. Epileptology of the first-seizure presentation; a clinical electroencephalographic, and magnetic resonance imaging study of 300 consecutive patients. Lancet 1998;352(9133):1007-11. 